\title{
O Trânsito das Culturas Populares como Política Pública: festivais de folclore e encontros de culturas populares e tradicionais
}

Bruno Goulart ${ }^{\mathrm{a}}$

Resumo: Este artigo reflete sobre as relações entre política cultural, festivais de cultura e culturas populares. O foco se dará na comparação entre os festivais de folclore (1951-1976) e os encontros de culturas populares e tradicionais (2000-presente), eventos concebidos como forma de política cultural. As reflexões apresentadas aqui são parte das conclusões de um projeto de pesquisa desenvolvido em 2019, que retoma dados de uma pesquisa de doutorado realizada entre 2014 e 2018 sobre os encontros e informações disponíveis na Revista Brasileira de Folclore (1950-1976) sobre os festivais. Entendo ambas as propostas como espaços de performance cultural que nascem na intersecção entre turismo/indústria cultural, políticas públicas e folclore/cultura popular. Porém, a maneira como cada um desses eventos articula essas várias dimensões é diferente. Desse modo, resgato a experiência desses eventos, abordando seu contexto de surgimento e traçando algumas possibilidades comparativas entre eles, com foco na relação estabelecida com as políticas culturais.

Palavras-chave: Trânsito cultural, Festivais de folclore, Políticas culturais.

Objetivo desse $\operatorname{artigo~}^{1}$ é apresentar algumas conclusões do projeto de pesquisa coordenado pelo autor, desenvolvido no ano de 2019, na Universidade da Integração Internacional da Lusofonia Afro-Bra-

a Professor do curso de Bacharelado em Antropologia (UNILAB). Doutor em Antropologia Social (UnB). Email: brunogoulart@unilab.edu.br. 
sileira (UNILAB). O tema da pesquisa surgiu como continuidade do doutorado, desenvolvido entre os anos de 2014 e 2018 (Silva 2018). $\mathrm{Na}$ tese de doutorado foi abordado as relações entre políticas culturais, performance cultural e a preservação, valorização e difusão de práticas culturais associadas à categoria culturas populares no Brasil contemporâneo. Com foco na experiência dos encontros de culturas populares e tradicionais - conceito que cunhei para designar uma proposta de evento que surge no Brasil por volta dos anos 2000 e une a dimensão de um festival cultural e de um fórum de discussões sobre políticas públicas -, a pesquisa de doutorado investigou como esses eventos surgiram graças a um renovado interesse de artistas e da academia pelo universo das culturas populares, à emergência de um circuito de apresentações 'culturais', gravações de discos e oficinas voltadas para os sujeitos e as práticas performáticas desse universo, assim como devido a um novo desenho das políticas culturais pós 2003.

Durante a investigação do doutorado entrei em contato com as várias edições da Revista Brasileira de Folclore (Campanha de defesa do folclore brasileiro, 1951-1976), disponíveis no acervo digital do Centro Nacional de Folclore e Cultura Popular. A partir daí, pude constatar que apesar da novidade representada pelos encontros de culturas populares e tradicionais, esses não eram sem precedentes na experiência brasileira, pois encontravam ecos na experiência da Comissão Nacional de Folclore (CNF) e, posteriormente, da Campanha de Defesa do Folclore Brasileiro (CDFB) e a sua idealização, organização e realização de diversos festivais de folclore que tomaram lugar em diferentes capitais do país entre as décadas de 1950 e 1970. Assim como os encontros de culturas populares e tradicionais contemporâneos, esses festivais foram incentivados pelo movimento folclórico como forma de política pública para a valorização, difusão e preservação do folclore.

Dessa maneira, entendo ambas as propostas - encontros e festivais de folclore - como espaços de performance cultural no formato de festivais de cultura, que nascem na intersecção entre turismo/indústria 
cultural, políticas públicas e folclore/cultura popular. Apesar das similaridades, acredito que cada uma dessas experiências guarde suas especificidades. Foi, então, com o intuito de explorar esse material de pesquisa que surgiu a ideia do projeto de pesquisa intitulado ' $O$ trânsito das culturas populares como política pública: um estudo comparativo entre os festivais de folclore (1950-1970) e os encontros de culturas populares e tradicionais (2000-2018)'.

Meu interesse aqui é apresentar algumas conclusões da pesquisa. $\mathrm{O}$ artigo será estruturado em quatro partes. Na primeira, procuro fazer uma rápida revisão bibliográfica sobre o tema do trânsito da cultura popular para os circuitos das indústrias musicais, do espetáculo, das artes e do turismo. Na segunda, abordo a experiência dos festivais de folclore explicitando seu contexto de emergência. Na terceira parte procuro refazer o mesmo caminho para o caso dos encontros. Por fim, traço alguns pontos de comparação entre essas duas experiências, dando uma atenção especial às relações entre preservação/salvaguarda, festivais, performance e cultura popular na experiência dos encontros e festivais de folclore.

\section{Trânsitos da cultura popular}

No Brasil, o conceito de cultura popular está intimamente relacionado com o de folclore. É importante sublinhar que essa associação se dá de modo diferente de outros países, principalmente anglo-saxões, nos quais o termo cultura popular se associou ora à cultura operária da época industrial (Storey 2003) ora aos movimentos contra culturais (Hall \& Jefferson 2003), enquanto o termo folclore se referia às práticas de um tempo 'pré-industrial'. Diferente dessa acepção, o entendimento do termo cultura popular que se estabeleceu no Brasil reúne "um conjunto heteróclito de formas culturais - música, dança, autos dramáticos, poesia, artesanato, ciência sobre a saúde, formas rituais, tradições de espiritualidade" (Carvalho 2010:44) e guarda íntima relações com o termo folclore, apesar dos conceitos pertencerem a momentos históricos distintos. 
Na América Latina, no geral, e no Brasil, especificamente, a partir da década de 1980, as práticas relacionadas a esse universo, principalmente as de caráter performático ${ }^{2}$, passam a transitar pelos circuitos da indústria cultural e do turismo (Trigueiro 2005). Nesse contexto, a cultura popular passa a circular por novos formatos - através de gravação de CDs, performances musicais e artísticas, imagens, vídeos etc. (Carvalho 2003; Vargas 2015; Guillen \& Lima 2006). Além disso, um grande número de rituais e festividades começou a se adequar às crescentes demandas do turismo e da publicidade (Canclini [1982] 1989; Silva 2007; Silva 2001; Mesquita \& Oliveira 2013; Goulart 2016; Spinelli 2008). Diante o cenário traçado, alguns pesquisadores têm destacado as implicações de ordem estética e simbólica desses processos, tais como: uma maior profissionalização dos detentores da cultura popular - pois agora essas tradições passam a ser vistas como um espetáculo artístico e/ou musical (e não mais apenas como brincadeiras ou práticas devocionais); a organização social na forma de 'grupos de apresentação'; o pagamento de cachê pelas apresentações; e a emergência de um mercado de produção cultural específica para esse universo (Osório 2012).

Tem-se acrescentado ainda que esses processos podem ser lidos como uma possibilidade de existência das práticas performáticas das culturas populares na contemporaneidade (Osório 2012) e que grande parte do crescimento, visibilidade e difusão da cultura popular e tradicional na América Latina é produto do seu trânsito pela indústria fonográfica, em festivais de dança e música popular tradicional e pelos meios de comunicação de massa (Canclini 2013).

Outros autores, porém, têm sido menos otimistas, ao chamar a atenção para os processos de apropriação cultural de tradições sagradas por parte de músicos da indústria cultural; assim como para os trânsitos da cultura popular, por meio de grupos, mestres e mestras no contexto de apresentações artísticas e musicais e suas implicações, tais como a redução temporal e semiótica. Ao conjunto desses processos José Jorge de Carvalho rem chamado de 'espetacularização 
da cultura popular' (Carvalho 2010). O termo designaria os "vários processos simultâneos" aos quais estaria submetida a cultura popular nesse deslocamento para o campo da indústria cultural (Carvalho 2010: 49).

Independente de tomar partido de alguma perspectiva - acreditamos que cada uma delas enfatiza um ponto e juntas nos ajudam a refletir sobre o tema aqui em questão, o que gostaria de sugerir é que existe toda uma literatura que trata sobre o trânsito da cultura popular que situa a emergência desses circuitos na década de 1980-1990. Argumento aqui que os encontros de culturas populares e tradicionais são eventos, percebidos como uma forma de política pública, que ocorrem no Brasil e que condensam propostas, reflexões e atores sociais desse momento do trânsito das culturas populares.

Dessa maneira, os encontros guardam em comum: a) a proposta de funcionarem enquanto espaços aglutinadores de práticas culturais diversificadas por meio categorias como culturas populares e tradicionais; b) a adoção do formato específico de um festival de cultura; e c) o fato de terem sido incentivados pelo poder público (principalmente por parte do Ministério da Cultura, extinto em 2019).

\section{Encontros de culturas populares e tradicionais}

Em meio à emergência de novos circuitos para a performance das culturas populares, surge a percepção das experiências de trânsito como forma de política cultural. É a partir desse cenário que irão surgir os encontros de culturas populares e tradicionais nos anos $2000^{3}$, enquanto forma de política cultural. Desse modo, esses eventos nascem na intersecção entre políticas públicas, indústria cultural/turismo e cultura popular/tradicional, organizados por ONGs, fundações, produtoras culturais e poder público. Eles foram financiados pelo Fundo Nacional de Cultura ou através de patrocínios de empresas de economia mistas, como a Petrobrás e a Eletrobrás, e fundações vinculadas a bancos públicos, como o Banco do Brasil e a Caixa Econômica Federal (Silva 2018). 
Os encontros de culturas populares serão realizados em capitais e em cidades do interior dos estados, principalmente em lugares de turismo ecológico ou que conte com a presença de parques e reservas ambientais, associando assim turismo ecológico e cultural. Do ponto de vista de suas programações eles procuram unir a dimensão de um festival de música e dança voltado para o universo da cultura popular, com a de um fórum de discussão sobre políticas públicas culturais (Silva 2018).

Estes eventos foram possibilitados por causa de um novo momento das políticas públicas culturais, inaugurado em 2003 (Nunes 2012; Barros \& Zivani 2011; Calabre 2015), que passa a contemplar de forma mais enfática a cultura popular e tradicional, ao levar em conta as discussões sobre patrimônio imaterial e diversidade cultural em organismos internacionais (Minc 2010; Lacerda, Marques \& Rocha 2010; Costa 2012; Ikeda 2013; Arantes 2009; Iphan 2010).

Nesse contexto de reformulação das políticas culturais nos anos 2000, uma das frentes de atuação da política cultural do MinC foi a valorização e difusão das culturas populares e tradicionais (Minc 2010). Inserido nessa frente, os encontros são vistos como espaços: a) de geração de renda e inserção de sujeitos da cultura popular na economia de mercado, b) de sensibilização da sociedade, de forma geral, às práticas e saberes desse universo, c) de intercâmbio entre essas várias tradições culturais - como forma de celebração da diversidade cultural brasileira ${ }^{4}$ - e d) de reivindicação política por meio da cultura - p ois neste contexto, as comunidades tradicionais passam a achar interessante "demonstrar 'performaticamente' sua cultura" como forma de obter maior acesso ao Estado (Cunha 2009:313).

É então como espaço de valorização, difusão e inserção da cultura popular em circuitos nacionais e internacionais que os encontros se colocam e são concebidos como estratégia de salvaguarda destes bens culturais. A ideia, então, é fundar um espaço de performance enquanto lugar estratégico de visibilidade e salvaguarda das práticas performáticas das culturas populares. Esta perspectiva parte da ideia de que ao 
se abrir novos espaços de performance, os grupos convidados teriam visibilidade, participariam de debates sobre políticas públicas, teriam acesso a gestores públicos, secretários do governo etc., e ainda conseguiriam uma fonte de renda, se fortalecendo e, por consequência, se preservando para as gerações futuras (Silva 2018).

Em linha gerais, os encontros foram concebidos como espaços de performance e discussões, voltadas para o universo das culturas populares e tradicionais, vistos e incentivados como forma de política cultural com o objetivo de difundir, valorizar e salvaguardar as culturas populares e tradicionais.

\section{Festivais de Folclore}

A experiência dos encontros de culturas populares e tradicionais, apesar da novidade que representam, não são sem precedentes na experiência das políticas culturais no Brasil. Desse modo, um paralelo pode ser traçado com a experiência do movimento folclórico brasileiro e a realização, por parte dos sujeitos envolvidos no movimento, de centenas de festivais de folclore ao longo dos anos 1950, 1960 e 1970.

A proposta dos festivais de folclore não são, contudo, uma novidade brasileira, mas um modelo de evento que tomou forma e propostas semelhantes nos Estados Unidos e alguns países da América Latina. Esses festivais foram vistos como uma maneira de oferecer de forma temporalmente e espacialmente concentrada uma performance das 'identidades nacionais' por meio de apresentações de grupos folclóricos (Kirshenblatt-Gimblett 1991; Bauman \& Sawin 1991; Guss 2000).

No Brasil, os festivais de folclore surgem no contexto de atuação do movimento folclórico, especificamente no âmbito da realização dos seus congressos ${ }^{5}$. Os congressos eram uma prática recorrente entre os folcloristas após a criação da Comissão Nacional de Folclore (CNFL) em 1947, vinculado ao Ministério das Relações Exteriores. $\mathrm{Na}$ programação de seus congressos os folcloristas sempre incorporaram exposições de artesanato e performances de folguedos populares. 
Os momentos de performance dos folguedos folclóricos foram nomeados de festivais de folclore - e não eram o evento principal, mas parte da programação dos congressos. Estes festivais eram gratuitos, realizados geralmente em espaços abertos com capacidade para um grande público.

No contexto dos congressos, o momento dos festivais foi percebido como "uma celebração do folclore brasileiro e da cordialidade que estaria presente em nossa cultura" (Vilhena 1997:220). Por isso, essas "apresentações folclóricas, que representavam o acontecimento mais festivo das jornadas de cada reunião, eram um ingrediente essencial e constitutivo desses encontros" (Vilhena 1997:217). Contudo, se os festivais de folclore têm espaço e centralidade nesse período inicial do movimento folclórico, é a partir de 1965 que eles se multiplicam, tornando-se recorrentes.

Com base em um levantamento na Revista Brasileira de Folclore (RBF) sobre a realização de festivais de folclore foi identificado a organização de uma centena desses festivais ${ }^{6}$. Alguns desses eventos, inclusive, passam a ser realizados com frequência anual, como o Festival Folclórico de Brasília, o Festival de Folclore de Olímpia (que acontece até hoje) e o Festival Internacional de Folclore, que se realizava anualmente em Curitiba (PR).

Os festivais começam a ganhar força no momento de constituição da Campanha de Defesa do Folclore Brasileiro ${ }^{7}$ (CDFB) - que substitui a Comissão Nacional de Folclore em 1958 - e se intensificam no governo da ditadura militar, a partir de 1964. Assim, no contexto do movimento folclórico, a disseminação dos festivais coincide com uma maior intervenção da ditadura na Campanha e a interrupção dos congressos que haviam marcado a atuação do período da CNFL (Vilhena 1997). No âmbito da Campanha contava-se com um departamento específico para organização desses eventos, vinculado à Divisão de Documentações, o setor de Festivais.

Uma das explicações para a proliferação dos festivais é que apesar das autoridades estaduais financiarem "semanas e congressos, atraí- 
dos pela dimensão de espetáculo desses eventos", tal financiamento não se dava "com a atividade cotidiana de pesquisa" da Comissão (Vilhena 1997:100). Outro ponto que explica o surgimento desses eventos foi o decreto $\mathrm{n}^{\circ} 56.747$, que instituiu o dia do folclore em 22 de agosto (Brasil 1965: 118). No artigo 2 do referido decreto podemos ler que o intuito da data é estimular "nos estabelecimentos de curso primário, médio e superior, as celebrações que realcem a importância do folclore na formação cultural do país" (Brasil 1965:118). Dessa maneira, com a instituição da data, os festivais se tornam uma de suas principais formas de comemoração e ganham "ares de política pública recomendada pelo Estado" (Soares 2011:13).

Apesar da realização dos festivais se concentrarem no estado de São Paulo (responsável pela organização de um terço do número total destes entre as décadas de 1950 e 1970), todas as regiões do país promoveram festivais no período, principalmente nas capitais dos estados. Nos eventos de caráter 'regional' os grupos que se apresentavam eram provenientes dos estados, regiões e/ou cidades vizinhas ao lugar de sua realização. Contudo, vez ou outra, como nos Festivais de Folclore de Brasília, eram reunidos grupos ou manifestações de origens provenientes de diversas partes do Brasil.

Segundo Lia Calabre (2005), esse intercâmbio cultural dentro das regiões e entre as regiões brasileiras é uma das propostas que aparecem de forma desenvolvida no Plano de Ação Cultural (lançado em agosto de 1973), mas não restrito ao universo do folclore. A proposta de intercâmbio cultural era vista aqui como uma forma de integração nacional no plano simbólico. Assim, em última instância os festivais de folclore foram percebidos como uma forma de efetivar o projeto de nacionalização do folclore e de sensibilizar o público sobre a importância da tradição popular nacional.

Além de serem espaços de performance da identidade nacional, os festivais foram vistos, também, como uma forma de preservação do folclore. A ideia de preservação passava pelo raciocínio de que com as então recentes mudanças econômicas (industrialização, migrações para 
as grandes cidades etc.) as tradições populares nacionais, por estarem associadas a certos modos de vidas ameaçados, também estariam em risco de desaparecimento. Diante esse quadro seria necessário, então, medidas de preservação da tradição (Carneiro 2008a; Almeida 1970).

\section{Festivais de cultura, nação, produção cultural, políticas culturais, salvaguarda e preservação}

Vimos até aqui que a experiência dos encontros de culturas populares e tradicionais e dos festivais de folclore estão relacionadas por articularem festivais de cultura como forma de política pública voltados para a preservação/salvaguarda da cultura popular performática. Apesar dessas semelhanças, porém, existem algumas características que os distinguem. Infelizmente está além do escopo do presente artigo desenvolver esses pontos à exaustão, mas gostaria de assinalar aqui alguns pontos de comparação entre a experiência dos festivais e dos encontros.

Uma das especificidades da conjuntura contemporânea dos encontros em relação ao momento dos festivais diz respeito ao financiamento. Como vimos, ambos recebem ou receberam financiamento público. Entretanto, o que o levantamento inicial tem mostrado é que o financiamento, no caso dos festivais de folclore, se deu principalmente nos âmbitos municipal e estadual, enquanto no caso dos encontros o repasse se deu no âmbito federal por meio, principalmente, do Ministério da Cultura. Além disso, agora temos outras instituições sociais que apoiam esses eventos, tais como empresas de economias mistas e fundações ligadas a bancos públicos. Dessa maneira, se a experiência dos encontros e dos festivais nos indica certa continuidade do diálogo com as instituições públicas voltadas para a cultura, nos encontros há maior diálogo com o governo federal e também a emergência de novos agentes financiadores da cultura popular, que não apenas o poder público.

Outro ponto de diferença que parece existir entre 'festivais' e 'encontros' diz respeito ao perfil dos grupos que compõem a programação de cada um. Enquanto os encontros reúnem grupos de perfis di- 
versificados - tanto os que se 'inspiram' na cultura popular para fazer apresentações musicais e artísticas, quanto os que 'adaptam' ritos e práticas da cultura popular para um contexto de apresentação cultural (Silva 2018), as programações dos festivais de folclore eram compostas majoritariamente por grupos folclóricos considerados 'tradicionais' constituído por brincantes e mestres ${ }^{8}$.

Outro paralelo que podemos traçar entre 'festivais de folclore' e 'encontros' diz respeito ao discurso da nacionalidade presente em cada um. A construção de uma identidade nacional marcou os estudos e o trânsito do folclore no contexto da Comissão Nacional de Folclore (CNFL) e da Campanha em Defesa do Folclore Brasileiro (CDFB) (Vilhena 1997; Carvalho 2004). Desse modo, a realização dos festivais se constitui em uma maneira de reproduzir, performaticamente, uma síntese da identidade brasileira e do que se acreditava ser sua essência. Por isso os festivais alegavam promover, com o trânsito dos grupos folclóricos para diferentes regiões, a integração cultural da nação. Nos 'encontros' além do discurso da nacionalidade não ser tão central, ele se configura de modo diferente, pois agora a ideia de nação brasileira passa a ser celebrada com ênfase no conceito de diversidade cultural. Dessa maneira, nos 'encontros' não se trata mais de celebrar a 'unidade nacional', mas a 'diversidade cultural brasileira', por meio da exibição de tradições culturais pertencentes a diferentes grupos étnicos-raciais e regiões do país.

Um quarto ponto de diferença entre encontros e festivais diz respeito à estrutura de produção e organização. Apesar de ainda não ter encontrado dados sobre os processos de organização e produção dos festivais, algumas informações provenientes do referido levantamento na Revista Brasileira de Folclore me fazem pensar que sua organização não contava com uma estrutura de produção profissional baseada nos padrões de eventos da indústria cultural. Um dos indícios que me levou a tal conclusão é que, para os folcloristas, organizar festivais não era visto de maneira similar à produção de shows, mas como ação de política pública - entendida como próxima das atividades de pesquisa 
e registro do folclore (Almeida 1970). Para Edson Carneiro ([1955] 2008a), por exemplo, o dinheiro não deveria se reverter jamais em cachê para os grupos, por exemplo. Isso implica que o pagamento de cachês não era algo recorrente ou mesmo uma prática institucionalizada, regida por contratos. No caso dos encontros, por outro lado, sua organização exige uma estrutura de produção considerável, incorporando vários procedimentos e fórmulas da indústria cultural, como a estrutura de palco e de produção do som, captação de recursos, prestação de contas, profissionais da produção cultural etc. Afora isso, agora, ao contrário dos festivais, as apresentações geralmente envolvem o pagamento de cachês e existência de contratos.

Essa diferença de produção e organização dos 'festivais' e 'encontros' implica em uma outra, relacionada à presença de dois atores sociais distintos: os folcloristas e os produtores culturais, respectivamente. Esses agentes se pautam por ideologias e formas de mediação distintas. Os folcloristas se afirmavam enquanto servidores públicos que estariam engajados - tinham uma 'missão' - na construção da identidade e memória nacional, e por isso se viam enquanto mediadores entre o folclore e o Estado-nação (Vilhena 1997; Carvalho 2004). Os produtores também se colocam enquanto engajados na valorização e disseminação da cultura popular, mas agora mais do que servidores públicos eles se tornam produtores culturais, que mediam a relação entre Estado, mercado e cultura popular (Carvalho 2004; Silva 2018).

Por fim, gostaria de desenvolver um pouco mais um último ponto de comparação entre 'festivais' e 'encontros', que diz respeito ao modo como articulam festivais de cultura, política cultural e cultura popular.

No contexto do movimento folclórico, a criação de circuitos de trânsito para o folclore foi vista como um modo de preservação do mesmo. Incialmente os folcloristas se voltaram para a criação de bibliotecas e arquivos nos quais o folclore iria circular transformado em documento e registro (estudos, pesquisas, gravações em áudio e vídeo, coleções de objetos etc.), ou ainda pela sua adoção enquanto 
disciplina ou pedagogia educacional nos níveis fundamental e médio de ensino (Carneiro 2008b). Esse cenário muda com o surgimento de espaços de apresentação no contexto dos festivais de folclore a partir da década de 1950 e, principalmente, de 1965.

Como argumentei, esses festivais passam a ser percebidos como uma forma de preservação do folclore. Um marco de tal entendimento é o artigo de Edson Carneiro, Preservação e Restauração dos Folguedos Folclóricos ([1955] 2008a). Para o folclorista, ao refletir sobre formas de preservação e restauração dos folguedos populares - além das formas tradicionais de preservação que passavam pela pesquisa e construção de acervos, "bastará multiplicar as suas oportunidades de apresentação para que tenhamos, afinal, bem vivos [os folguedos], como parte integrante da paisagem cultural" (Carneiro [1955] 2008a:105). Isso porque, de acordo com Carneiro, "o intervalo de um ano entre uma e outra apresentação [como é caso da maioria das festas religiosas ou folguedos folclóricos] se revelou demorado demais em relação com o ritmo com que se processavam, sob a premência da hora, as transformações econômicas de superfície" ([1955] 2008a:101).

Porém, Edson Carneiro ([1955] 2008a) pondera sobre esse tipo de ação de preservação/restauração. Para ele, possibilitar novos espaços de apresentação se tratava de uma intervenção, e para que esse tipo de intervenção não impactasse "o caráter de legítima expressão do povo" dos folguedos, seria necessária "uma extrema discrição" (Carneiro [1955] 2008a: 103). Essa discrição era necessária de modo a dar liberdade para o grupo, ajudando apenas no que fosse imprescindivel ${ }^{9}$ e promovendo sua apresentação em público (Carneiro [1955] 2008a). Segundo Vilhena, o texto é marcado por um paradoxo, pois se "aos fenômenos folclóricos se atribui uma autenticidade e uma espontaneidade decorrentes de sua origem popular, qualquer interferência externa, mesmo tendo como objetivo a proteção do folguedo, representaria uma potencial ameaça" (Vilhena 1997:187). O ponto crucial do artigo de Carneiro ([1955] 2008a) é, então, a definição de fronteiras que separam interferências adequadas e inadequadas (Vilhena 1997). 
A experiência dos encontros, por sua vez, remete a um contexto mais atual, o que implicou na presença de outras orientações e discursos para se justificarem enquanto política cultural. Como vimos, desde a década de 1980 a experiência das manifestações performáticas das culturas populares tem sido marcada por sua inserção nos circuitos das indústrias cultural e do turismo. Em meio a esse contexto de surgimento de novos circuitos para a performance das culturas populares, surge também a percepção das experiências de trânsito como forma de política cultural ${ }^{10}$. Dessa maneira, foi incentivado também a circulação das culturas populares em contextos de shows, festivais, gravações de CDs, DVDs etc. Esse tema é desenvolvido Plano Setorial das Culturas Populares, principalmente no item que se refere ao programa de Difusão das Culturas Populares, que tem como um dos objetivos "a divulgação das culturas populares em suas comunidades de origem e para além delas, dentro e fora do país” (Minc 2012:46). Divulgação essa que deveria se concretizar por meio de ações como o "fomento a festivais, festas, encontros, a veiculação de conteúdos em meios de comunicação, o intercâmbio entre seus praticantes, e outras formas que permitam ampliar a circulação dessas culturas" (Minc 2012:46).

Agora, porém, ao contrário da linguagem da 'preservação' - que está associada à experiência dos festivais de folclore, o termo central é 'salvaguarda'. A mudança não é apenas de nome, mas de perspectiva, acarretando implicações no entendimento da referida relação entre festivais e política cultural. Assim, o que é alvo de salvaguarda na política do patrimônio imaterial não são os produtos culturais em si, mas os sujeitos e relações sociais das quais eles dependem. Segundo Letícia Vianna \& João Gabriel Teixeira, o "foco está, sobretudo, na valorização e garantia objetiva das condições concretas para a realização dos processos de produção, e não nos produtos culturais propriamente" (2008:5). Desse modo, mais do que preservar a performance de uma forma de expressão ritual e/ou festividade, o trânsito dessas práticas por eventos como os 'encontros' é lido como novos formatos estratégicos experimentados pelos sujeitos das culturas populares 
como incentivo para a continuidade de suas práticas culturais nos seus contextos tradicionais.

Esse entendimento foi influenciado, por sua vez, por debates e discussões realizados no âmbito do patrimônio imaterial, que colocou como um dos objetivos da política a difusão, ou divulgação, dos bens culturais reconhecidos como patrimônio (Brasil 2000). Nesse sentido, existe um certo consenso de que a inserção de determinados bens patrimoniais nos circuitos do turismo e do espetáculo pode ser desejável e até mesmo funcionar como uma estratégia para a 'salvaguarda' dos bens culturais 'imateriais' (Arantes 2009; Osório 2012). Essa inserção, porém, deve respeitar certos limites impostos pelos detentores das culturas populares (e do patrimônio imaterial), assim como se basear em padrões éticos (Sandroni 2005; Minc 2005), tais como respeitar a autonomia e protagonismo dos mestres, mestras e seus grupos, desenvolver técnicas e estratégias de produção cultural para a 'apresentação' da cultura popular e o pagamento de cachês dignos, que levem em conta a distribuição equitativa dos recursos investidos na realização dos 'encontros'.

\section{Considerações finais}

Ao longo desse artigo procurei mostrar algumas aproximações entre a experiência dos 'festivais de folclore', que se desenvolveram nos finais de década de 1950 até início da de 1970, e dos 'encontros de culturas populares e tradicionais', que se disseminaram nos anos 2000. Sobre a semelhança entre esses eventos, ambos surgiram tendo em vista três pontos centrais em comum: a) a proposta de levar mestres e mestras da cultura popular e seus grupos para um novo contexto de performance; b) a visão dessa mudança de contexto da cultura popular enquanto uma ação de política pública; e c) a ideia de que esses eventos seriam uma maneira de incentivar, celebrar, difundir, preservar e salvaguardar o(a) folclore brasileiro/cultura popular.

As diferenças de contexto dessas duas experiências ocasionam, contudo, em particularidades como vimos acima. Um ponto central 
destacado é o modo como estão articulados com o discurso da política pública. Enquanto os festivais de folclore são percebidos enquanto uma forma de preservação da performance em si, os encontros são vistos como uma forma de divulgação e valorização dos detentores das tradições performáticas para novos públicos e contextos, o que era visto, por sua vez, como uma forma de incentivar e fortalecer essas performances em seus 'contextos tradicionais'.

\section{Notas:}

1 Uma primeira versão desse trabalho foi apresentada no $\chi$ Seminário Internacional de Políticas Culturais, que ocorreu na Casa Fundação Rui Barbosa, em maio de 2019.

2 Quando falo de cultura popular de caráter performático me refiro principalmente àquelas expressões aonde expressões musicais, corporais e visuais estão presentes.

3 O número destes encontros realizados entre os anos 2000 e 2016 soma mais ou menos 100 eventos. O que marca este momento é a recorrência de várias edições de um mesmo encontro, como é o caso do Encontro de Culturas Tradicionais da Chapada dos Veadeiros, com 16 edições realizadas. Como outros exemplos, podemos citar ainda: o Encontro dos povos do Grande Sertão Veredas (Chapada Gaúcha MG, 14 edições); Vozes de Mestres: encontro internacional das culturas populares (itinerante, 5 edições); o Encontro de Culturas Populares e Tradicionais (itinerante, 8 edições); o Encontro Mestres do Mundo (Crato e Fortaleza - CE, 9 edições); e o Encontro de Bonito (GO) de Culturas Populares (Formosa - GO, 7 edições).

4 Por isso inclusive a preferência pelo uso do plural no título de vários dos encontros.

5 Em 1951, por exemplo, foi realizado na cidade do Rio de Janeiro o Congresso Brasileiro de Folclore; em 1952 temos o Festival Folclórico de Maceió; em 1953 o II Congresso Brasileiro de Folclore, em Curitiba; em 1954 o Congresso Internacional de Folclore, realizado na cidade de São Paulo; e, em 1957, o III Congresso brasileiro de Folclore, realizado em Salvador.

6 No período que vai de 1958 a 1964, o número de festivais de folclore realizados foi tímido, ficando em torno de um ou dois festivais por ano. Contudo, no ano de 1965 podemos encontrar referências a sete festivais de folclore na Revista Brasileira de Folclore (RBF). Em 1966 temos um pequeno recuo no número, sendo apenas 4 festivais nacionais referidos na RBF. Porém, nos anos subsequentes temos um aumento: em 1967, 11 festivais; em 1968, 15; 1969, 12; 1970, 10; 1971, 11; 1972, 15; 1973, 6. Apesar da RBF ter tido edições até o ano de 1976, a última referência aos festivais data de 1973 .

7 A campanha era um projeto antigo do movimento folclórico em busca de sua institucionalização na estrutura estatal. Segundo Vilhena (1997), esse desejo de ins- 
titucionalização passava pela ideia de que a defesa do folclore não era de responsabilidade de estudiosos ou homens de boa vontade, mas antes tarefa do Estado. Isso porque o movimento folclórico, organizado em torno da CNFL, contava apenas com a dedicação dos folcloristas, que não recebiam nenhuma remuneração ou fundo previsto para a realização de eventos, pesquisas ou planos de salvaguarda (Vilhena 1997). Com a criação da Campanha, a ideia era mudar esse quadro, e fazer com que o movimento contasse com recursos garantidos para suas atividades. Porém, se com a constituição da Campanha pretendia-se contornar essas limitações, garantindo verbas para as atividades de pesquisa, esse quadro irá se alterar pouco durante os anos da CDFB. Apesar de nos seus primeiros anos Vilhena (1997) apontar um sobressalto nas atividades de pesquisa do movimento folclórico, com a inauguração de bibliotecas, convênios com universidades, registro fonográfico e fotográfico do folclore etc., esse momento não dura muito. Em 1964 temos a deposição do presidente João Goulart e o golpe civil-militar. Na época era Edson Carneiro quem estava à frente da CDFB. Com o golpe, ele é afastado por causa de suas posições marxistas e quem assume em seu lugar é Renato Almeida (Vilhena 1997). Apesar do nome de Renato Almeida estar estreitamente ligado ao movimento desde a CNFL, ele assume a campanha "num quadro marcado pelo afastamento de vários funcionários e em meio a enormes dificuldades financeiras" (Vilhena 1997:106).

8 Essa hipótese é feita com base no nome dos grupos que conformam a programação dos festivais de folclore, que muitas vezes se referem à tradição performática que pertencem (congado, catira, reisado etc.) e ao lugar de origem (cidade e/ou estado). 9 Por isso, o autor defende que o dinheiro não deveria se reverter jamais em cachê. A ajuda em dinheiro deveria ser limitada ao máximo e, quando ocorresse, apenas a fim de ajudar em coisas específicas (como compra de fardamentos, manufatura de estandartes, instrumentos etc.) (Carneiro [1955] 2008a). Assim, essa ajuda deveria ter caráter excepcional, para nunca tornar o grupo dependente dela (Carneiro [1955] 2008a).

10 Paralelo e em diálogo com essa proposta um dos circuitos de trânsito para as culturas populares que emergiu aqui foram o das universidades, escolas e instituições de ensino de modo geral. Dois projetos são dignos de nota. $\mathrm{O}$ primeiro é a Acção Griô, desenvolvida através de uma parceria da Associação Grãos e luz Griô e o MinC - a partir da Secretaria de Cidadania Cultural (SCC) (Ação griô: uma política pública..., 2017 - [http://graosdeluzegrio.org.br/acao-grio-nacional/; acesso em 22/09/2017]). Outro projeto atual, mas voltado especificamente para o ensino superior, foi o Encontro de Saberes, que teve início em julho de 2010. Este é um projeto do Instituto Nacional de Ciência e Tecnologia de Inclusão no Ensino Superior e na Pesquisa (INCTI), com sede na Universidade de Brasília, realizado em parceria com o Ministério da Cultura - através da Secretaria da Identidade e da Diversidade Cultural (SID/MinC) - e com o Ministério da Educação - por meio da Secretaria de Educação Continuada, Alfabetização e Diversidade (SECAD/MEC). O projeto, coordenado pelo antropólogo José Jorge de Carvalho, busca trazer às universidades, na condição de professores, mestras(es) da cultura tradicional, com o intuito de promover um diálogo e uma experimentação pedagógica e epistêmica com os saberes tradicionais (Carvalho \& Águas 2015). 


\section{Referências:}

ALMEIDA, Renato. 1970. "Folclore e Turismo Cultural”. Revista Brasileira de Folclore, 10(28):199-203.

ARANTES, Antonio. 2009. "Sobre inventários e outros instrumentos de salvaguarda do patrimônio cultural intangível: ensaio de antropologia pública”. Anuário Antropológico, 2007-2008: 173-222.

BARROS, J. M. \& ZIVIANI, P. 2011. "O programa cultura viva e a diversidade cultural”. In BARBOSA, F. \& CALABRE, L. (eds.). Pontos de cultura: olhares sobre o Programa Cultura Viva, pp. 61-88. Brasília: IPEA.

BAUMAN, R. \& SAWIN, P. 1991. "The politics of Participation in Folklife Festivals”. In KARP, I. \& LAVINE, S. (eds.). Exhibiting Cultures: The poetics and politics of museum display, pp. 288-314. Washington / London: Smithsonian Institution Press.

BRASIL. 2000. Decreto 3551, de 4 de agosto de 2000. Brasília, DF. . 1965. "Decreto no 56.747, de 17 de agosto de 1965". Revista Brasileira de Folclore, 5(12): 118.

CALABRE, Lia. 2015. "Notas sobre os rumos das políticas culturais no Brasil nos anos 2011-2014”. In: RUBIM, A., BARBALHO, A. \& CALABRE, L. (eds.): Politicas Culturais no Governo Dilma, pp. 33-48. Salvador: EDUFBA.

2005. "Política Cultural no Brasil: um histórico". Trabalho apresentado no I Encontro de Estudos Multidisciplinares em Cultura (Enecult), Salvador-BA. (www.cult.ufba.br/enecul2005/LiaCalabre.pdf; acesso em 29/06/2016).

CANCLINI, Nestor G. [1989] 2013. Culturas Hibridas: estratégias para entrar e sair da modernidade. São Paulo: EdUSP.

[1982] 1989. Las Culturas Populares en el Capitalismo. México: Nueva Imagen.

CARNEIRO, Edson. [1955]2008a. "Proteção e restauração dos folguedos populares”. In CARNEIRO, E. (ed.): A Dinâmica do Folclore, pp. 97-110. São Paulo: Martins Fontes.

[1955]2008b. Formação de novos quadros em folclore. In CARNEIRO, E. (ed.): A Dinâmica do Folclore, pp. 122-125. São Paulo: Martins Fontes.

CARVAlHO, J. \& ÁGUAS, C. 2014. "Encontro de Saberes: um desafio teórico, político e epistemológico”. Trabalho apresentado no I Colóquio Internacional Epistemologias do Sul: Aprendizagens Globais Sul-Sul, Sul-Norte, Norte-Sul, Coimbra-PT. (http://alice.ces.uc.pt/coloquio_alice/wp-content/ uploads/2015/08/Livro_DD.pdf; acesso em 21/11/2017).

CARVALHO, José J. 2003. “As Culturas Afro-americanas na Ibero-américa: o negociável e o inegociável”. In CANCLINI, N. (ed.): Culturas da IberoAmérica: diagnósticos e propostas para seu desenvolvimento, pp: 101-138. São Paulo: Ed. Moderna. 
CARVALHO, José J. 2004. "Metamorfoses das tradições performáticas afrobrasileiras: de patrimônio cultural a indústria do entretenimento". Série Antropologia, 354:1-21. 2010. “'Espetacularização' e 'canibalização' das culturas populares na América Latina”. Revista Anthropológicas, 21(1):39-76.

COSTA, Eliane. 2012. "A Política de Patrocínios e a Ação da Petrobrás junto aos Festivais de Artes Cênicas no Brasil”. Repertório, 19(2):132-133.

CUNHA, Manuela C. 2009. Cultura com Aspas. São Paulo: Cosac Naify.

GOULART, Bruno. 2016b. "Turismo Cultural e Patrimônio Imaterial nas Cavalhadas de Pirenópolis". Trabalho apresentado no I Seminário de Turismo e Cultura, Rio de Janeiro-RJ. (http://culturadigital.br/visiteacasaderuibarbosa/ files/2016/08/Anais-do-I-Semin\%C3\%A1rio-Nacional-de-Turismo-e-Cultura. pdf; acesso em 15/12/2016).

GUILLEN, I. \& LIMA, I. 2006. "Os Maracatus-Nação do Recife e a Espetacularização da Cultura Popular”. SAECULUM - Revista de História, $14(1): 183-198$.

GUSS, David. 2000. The Festive State: race, ethinicity, and nationalism as cultural performance. Berkeley/ Los Angeles/ Londres: University of California Press.

HALL, S. \& JEFFERSON, T. 2003. Resistance through Rituals: Youth subcultures in post-war Britain. Londres: Routledge.

IKEDA, Alberto. 2013. "Culturas Populares no Presente: fomento, salvaguarda e devoração”. Estudos Avançados, 27(79):173-190.

IPHAN (Instituo do Patrimônio Histórico e Artístico Nacional]. 2010. Os Sambas, as Rodas, os Bumbas, os Meus e os Bois: Princípios, ações e resultados da política de salvaguarda do patrimônio cultural imaterial no Brasil, 2003-2010. Brasília: IPHAN.

KIRSHENBLATT-GLIMBETT, Barbara. 1991. "Objects of Ethnography”. In KARP, I. \& LAVINE, S. (eds.): Exhibiting Cultures: The poetics and politics of museum display, pp. 386-443. Washington / London: Smithsonian Institution Press.

LACERDA, A., MARQUES, C. \& ROCHA, S. 2010. "Programa cultura Viva: uma nova política do Ministério da Cultura”. In RUBIM, A. (ed.): Políticas Culturais no Governo Lula, pp. 111-132. Salvador: EDUFBA.

MESQUITA, É. EO OLIVEIRA, A. 2013. "Folia do Divino Espíito Santo em Pirenópolis: Apontamentos Bibliográficos". Trabalho apresentado no III Simpósio Nacional de História, Iporá-GO.

MINC [Ministério da Cultura]. 2005. Anais do I Seminário Nacional de Políticas Públicas para as Culturas Populares. São Paulo/Brasília: Inst. Polís/MinC.

2010. Plano Setorial Para as Culturas Populares. Brasília: MinC/SID. 2012. Plano Setorial Para as Culturas Populares. Brasília: MinC/SCC. 
NUNES, Ariel. 2012. Por um 'do-in antropológico': Pontos de cultura e os novos paradigmas nas políticas públicas culturais. Dissertação de Mestrado. Goiânia: Universidade Federal de Goiás.

OSÓRIO, Patrícia. 2012. "Os Festivais de Cururu e Siriri: mudanças de cenários e contextos na cultura popular”. Anuário Antropológico, 2011/2012:237-260.

SANDRONI, Carlos. 2005. "Circuitos de difusão no mercado: contra ou a favor". Trabalho apresentado no I Seminário Nacional de Políticas Públicas para as Culturas Populares, Brasília-DF.

SILVA, Bruno. 2018. Trânsitos das culturas populares: política pública, produção, difusão e salvaguarda nos Encontros de Culturas Tradicionais. Tese de Doutorado. Brasília: Universidade de Brasília.

SILVA, José M. 2007. O Espetáculo do Boi-Buumbá: Folclore, Turismo e as Multíplas Alteridades em Parintins. Goiânia: Ed. da UCG.

SILVA, Mônica. 2001. "As Cavalhadas de Pirenópolis: Um estudo sobre sociedade, festas e espaço urbano (1940-1988)”. História Revista, 6(1):135-162.

SOARES, Ana Lorym. "Folclore e políticas culturais no Brasil nas décadas de 1960/1970". Trabalho apresentado no II Seminário Internacional de Políticas Culturais, Rio de Janeiro-RJ. (www.casaruibarbosa.gov.br/dados/ DOC/palestras/Politicas_Culturais/II_Seminario_Internacional/FCRB_ AnaLorymSoares_Folclore_e_politicas_culturais_no_Brasil_nas_decadas_ de_1960-1970.pdf; acesso em 29/06/2016).

SPINELLI, Céline. 2008. "Em Pirenópolis: as cavalhadas e projetos de fomento ao turismo local". Trabalho apresentado no XXXII Encontro Anual da Anpocs, Caxambu-MG.

STOREY, John. 2003. Inventing popular Culture. Oxford: Blackwell Publishing.

TRIGUEIRO, Osvaldo. 2005. "A Espetacularização das culturas populares: ou produtos culturais folkmidiáticos”. Revista Internacional de Folkcomunicação, 5(1):1-9.

VARGAS, Herom. 2015. "Chico Science \& Nação Zumbi: Hybridity and Experimentation in the Manguebeat Movement". In ULHÔA, M., AZEVEDO, C. \& TROTTA, F. (eds.). Made in Brazil: Studies in Popular Music, pp. 121-132. Nova York/ Londres: Routledge.

VIANNA, L. \& TEXEIRA, J. 2008. "Patrimônio imaterial, performance e identidade". Trabalho apresentado no IV ENECULT, Salvador -BA.

VILHENA, Luís R. 1997. Projeto e Missão: o movimento folclórico brasileiro (1947. 1964). Rio de Janeiro: Funarte/ Fundação Getúlio Vargas.

Abstract: This article aims to develop the connections between cultural policies, culture festivals and popular culture. Our objective is to compare 'folklore festivals' (1951-1976) and 'traditional and popular culture 
encounters' (2000-presente). The research here presented is part of the conclusions of a research project developed in 2019. The research revisit my PHD thesis data about the 'encounters', research done between 2014-2018, and the data about the 'folklore festivals' present in the Revista Brasileira de Folclore (1950-1976). I understand both experiences as performance places that emerge in the intersection of tourism/cultural industries, public policies and folklore/popular culture. Despite the connections, both events articulate each of these themes in a particular way. Therefore, I compare the experiences of the folklore festivals and the traditional and popular culture encounters, showing how they emerge and emphasizing the relation between cultural policies and them.

Keywords: Cultural transit, Folklore festivals, Cultural policies.

Recebido em fevereiro de 2020.

Aprovado em maio de 2021. 